\title{
Neuropsychological deficits in patients with persistent symptoms six months after mild head injury
}

Citation for published version (APA):

Bohnen, N., Jolles, J., \& Twijnstra, A. (1992). Neuropsychological deficits in patients with persistent symptoms six months after mild head injury. Neurosurgery, 30(5), 692-696.

https://doi.org/10.1097/00006123-199205000-00007

Document status and date:

Published: 01/01/1992

DOI:

10.1097/00006123-199205000-00007

Document Version:

Publisher's PDF, also known as Version of record

\section{Please check the document version of this publication:}

- A submitted manuscript is the version of the article upon submission and before peer-review. There can be important differences between the submitted version and the official published version of record.

People interested in the research are advised to contact the author for the final version of the publication, or visit the DOI to the publisher's website.

- The final author version and the galley proof are versions of the publication after peer review.

- The final published version features the final layout of the paper including the volume, issue and page numbers.

Link to publication

\footnotetext{
General rights rights.

- You may freely distribute the URL identifying the publication in the public portal. please follow below link for the End User Agreement:

www.umlib.nl/taverne-license

Take down policy

If you believe that this document breaches copyright please contact us at:

repository@maastrichtuniversity.nl

providing details and we will investigate your claim.
}

Copyright and moral rights for the publications made accessible in the public portal are retained by the authors and/or other copyright owners and it is a condition of accessing publications that users recognise and abide by the legal requirements associated with these

- Users may download and print one copy of any publication from the public portal for the purpose of private study or research.

- You may not further distribute the material or use it for any profit-making activity or commercial gain

If the publication is distributed under the terms of Article $25 \mathrm{fa}$ of the Dutch Copyright Act, indicated by the "Taverne" license above, 


\title{
Neuropsychological Deficits in Patients with Persistent Symptoms Six Months after Mild Head Injury
}

\author{
N. Bohnen, M.D., Ph.D., J. Jolles, Ph.D., and A. Twijnstra, M.D., Ph.D. \\ Deparment of Newropsychology and Psychobiology, Universily of Limburg (NB. JI), and Departmen of Neurology. University Hospital (AT), \\ Macastricht, The Netherlands
}

\begin{abstract}
There is much debate on the nature and duration of cognitive deficits and postconcussive symptoms (PCS) after mild head injury. Most studies performed so far have compared head-injured patients with subjects who had not suffered a concussion, instead of directly comparing patients with and without persistent $\mathrm{PCS}$. The present study examined whether patients with PCS ( $\mathrm{n}=9$ ) about 6 months after an uncomplicated mild head injury performed less well on selected neuropsychological tests than patients with mild head injuries who did not have PCS $(n=9)$ and bealthy controls ( $\mathrm{n}=$ 9). Patients with PCS were individually matched with controls for the time elapsed after the injury, age, sex, and education. We found that patients with PCS performed less well on tests of divided and selective attention than both patients without PCS and healthy controls. It is concluded that cognitive deficits may be present up to 6 months after mild head injury when symptoms persist. The findings indicate that patients with mild head injury and subjective symptoms may manifest demonstrable cognitive deficits. (Newrosurgery 30:692-696, 1992)
\end{abstract}

Key words: Attention, Mild head injury, Postconcussive symptoms

\section{INTRODUCTION}

The cognitive deficits and postconcussive sequelae caused by severe head injury have been well established (5). Mild head injury (MHI) is much more common than severe head injury, and many patients have subjective impairments as a result of their head injury (3). There has been much debate over the years as to whether minor head injuries result in significant persistent cerebral damage and, if present, whether this damage is demonstrable by objective methods. Neuropsychological investigations have been carried out over the past 20 years to evaluate behavioral and cognitive dysfunctions in patients with MHI. Whereas gross deficits in intelligence or memory have not been reported in conjunction with minor head injury $(8,10,18)$, subtle impairments in the rate of information processing and attention have been found $(12,13,15,22)$. An important question is how long these cognitive deficits will persist. Neuropsychological and psychosocial difficulties persisting 3 to 6 months after minor head injury have been reported $(2,17,26)$. The results of several other studies, however, do not indicate decreased cognitive functioning about 1 month after minor head injury $(8,10,18)$. The conflicting results may be because of the heterogeneity of the subjects, the different time intervals after injury, the sensitivity of the selected cognitive tests in detecting post traumatic brain dysfunction, and the appropriateness of the control group. Most studies performed so far have compared head-injured patients with subjects who had not suffered a concussion, instead of directly comparing patients with and without persistent postconcussive symptoms (20). Evidence is growing to indicate that cognitive deficits may be limited to a subgroup of MHI patients, for instance, those with subjective complaints $(9,10,17)$.

The aim of the present study, therefore, was to test the hypothesis that patients with postconcussive symptoms 6 months after MHI have cognitive dysfunctions as compared with matched, symptom-free MHI patients and healthy control subjects. A specific impairment of attention after MHI has been shown by a number of studies $(10,11,15)$. Therefore, tests that measure diferent aspects of attention were included in the test battery.

\section{PATIENTS AND METHODS}

\section{Patients}

Patients with persistent $\mathrm{PCS}(\mathrm{n}=9)$ were selected from a cohort of patients with $\mathrm{MHI}$. The criteria for inclusion in the study were as follows: an interval of about 6 months since the injury, a period of posttraumatic amnesia not exceeding 60 minutes, a period of unconsciousness of less then 15 minutes, a Glasgow Coma Scale score (28) of 15 at admission, and no serious traumatic physical complication (including the absence of orthopedic injury). Patients who had drunk alcohol at the time of the trauma or who had a skull fracture were excluded. None of the subjects was involved in litigation or in seeking compensation, and none had a history of neuropsychiatric disorder. Consequently, 25 patients ( 7 female, 18 male) were excluded from the study. Forty-six patients ( 23 lemale, 23 male) with an uncomplicated MHI with no premorbid compromising condition were selected. The causes of the injury were traffic $(n=33)$, falls $(n=6)$, fights $(n=1)$, sports $(\mathrm{n}=5)$ and accidents at work $(\mathrm{n}=1)$. Six patients became unavailable lor follow-up. There were 9 patients with persistent PCS at 6 months after the uncomplicated MHI $(22 \%)$. The causes of the injury within the PCS group were traffic $(\mathrm{n}=7)$, fights $(\mathrm{n}=1)$, and sports $(\mathrm{n}=1)$.

The MHI patients who had recovered completely and had no PCS 6 months after injury $(n=9)$ were selected from the same population on the basis of matching criteria with the patients with persistent PCS. The uninjured group $(n=9)$ was selected from a pool of healthy volunteers who had not suffered a concussion. Both the MHI patients without PCS and the healthy volunteers were individually matched with the patients with $\mathrm{PCS}$ for age ( \pm 6 years), sex, and education ( \pm 1 level) (29). The 7-point scale of Verhage (29) represents 7 different levels of educational achievement based upon the Dutch scholastic system. Each group consisted of 5 male and 4 female subjects. Mean age, time elapsed atter the trauma, and the educational level are presented in Table 1. All subjects gave their informed consent.

\section{Postconcussive symproms}

A checklist of postconcussive symptoms, which included headache, nausea, dizziness, difficulty with concentration and memory, fatigue, and sleep disturbances was completed for each subject. As these symptoms also occur in healthy individuals (8), the symptoms were scored 
TABLE 1

Mean Age. Time after the Injury, and Edwational Level of

Patients with Persistent Postconcussive Symptoms and Controls

\begin{tabular}{|c|c|c|c|}
\hline & \multirow[b]{2}{*}{$\begin{array}{l}\text { Patients with } \\
\operatorname{PCS}^{b}(\mathrm{n}=9)\end{array}$} & \multicolumn{2}{|c|}{ Controls } \\
\hline & & $\begin{array}{c}\text { Patients } \\
\text { without } \\
\operatorname{PCS}(\mathrm{n}=9)\end{array}$ & $\begin{array}{l}\text { Healthy } \\
\text { Subjects } \\
(\mathrm{n}=9)\end{array}$ \\
\hline Age $(y r)$ & $30.4(11.7)$ & $28.5(11.2)$ & $30.1(11.7)$ \\
\hline Education: & $4.7 \quad(0.6)$ & $4.9 \quad(0.8)$ & $5.0(1.2)$ \\
\hline $\begin{array}{l}\text { Time after injury } \\
\text { (mo) }\end{array}$ & $5.89(0.89)$ & $6.17(1.09)$ & \\
\hline
\end{tabular}

a The standard deviation is given in parentheses.

${ }^{\circ} \mathrm{PCS}$, postconcussive symptoms.

categories taken from Verhage R: Intelligentic en leefijd.

Doctoral dissertation. Assen, The Netherlands, 1964.

for the absolutely or relatively increased appearance of the symptom after the injury as compared with the pretraumatic condition. Of the 9 patients with persistent $\mathrm{PCS}, 8$ complained of three symptoms or more, and one patient complained of two symptoms. By definition, patients without PCS did not report any symptom 6 months after the injury.

\section{Psychometric tests}

The following tests were used:

1. Memory task. A visual, computer-assisted version of the Auditory Verbal Learning $\mathbb{T}$ est (19) was presented on a portable microcomputer (4). The test consists of a list of 15 monosyllabic, meaningful words, which are presented for 1 second at 1 -second intervals. At the end of the trial, the subjects recall the words. Five trials were carried out. The variable used in this study was the total number of correct words over all trials.

2. The Stroop Color Word Interference Test. This test consists of three subtasks (19). The tests examines the speed at which 100 color names (yellow, green, red, and blue) are read (Subtask I) and the speed at which 100 colored spots are named (Subtask II). Subtask III again involves 100 color names, but the printing ink is different from the color name; the speed at which the color of the printing ink of the words is named is taken as the test variable. The color word interference score-which can be taken as a measure of selective attention (14)-results from the subtraction of the time needed for Subtask II from that of Subtask III (III minus II), and was used as the cognitive parameter.

3. The computerized diwided attention task. In this test, dots were presented at irregular time intervals within a fixed rectangular matrix measuring $6-10$ on a monitor screen measuring $20-28 \mathrm{~cm}$ (Vienna test system, Schuhfried GmbH, Vienna, Austria). The subject was instructed to press a button when four dots formed a square the signal). Each square was illuminated for three seconds whille other dots appeared and disappeared. The maximum number of different points "moving" simultaneously was three. Sixty signals were presented during the total testing time of 12.5 minutes. The mear reaction time and the number of omissions were recorded and used as the cognitive measures.

\section{Statistical analysis}

The first step in the analysis was to assess by MANOVA (27) whether there was an overall difference between the two groups for all cognitiwe parameters together. This multivariate approach is particularly suitable for analyzing differences between grotups when subjects are examined by more than one parameter, in that the same degree of protection against Type I errors as that for the general analysis is maintained for each comparison. In the second step, separate univariate analyses per cognitive parameter were carried out. Duncan"s multiple range test was used as a post hoc test to evaluate significant main effects (27). Probabilities greater than 0.05 were considered nonsignificant. Ranks over all observations were calculated for scores that did not approximate a normal distribution (7).

\section{RESULTS}

Multivariate analysis yielded a significant "group" effect [Wilks lambda $=0.42$; equivalent multivariate $\mathrm{F}(8,42)=2.82 ; P<0.05$ ], Therefore, separate univariate tests per cognitive parameter were carried out. Mean data and $F$ values are presented in Table 2 . With respect to the verball learning test, the ANOVA failed to achieve a significant difference between groups ( $P<0.1)$. There was a significant overall group effect of the Stroop Color Word Interference Score (III minus II). Post hoc tests indicated that patients with PCS had significantly higher interference times than both control groups.

Analysis of the scores for the divided attention task revealed an overall significant group effect for the mean reaction time. Post hoc tests indicated that the patients with PCS were significantly slower than

TABLE 2

Results of the Neuropsychological Tests

\begin{tabular}{|c|c|c|c|}
\hline \multirow[b]{2}{*}{ Test } & \multirow[b]{2}{*}{ Patients with $\operatorname{PCS}(\mathrm{n}=9)$} & \multicolumn{2}{|c|}{ Controls } \\
\hline & & $\begin{array}{l}\text { Patients whout } \\
\operatorname{PCS}(\mathrm{m}=9)\end{array}$ & $\begin{array}{c}\text { Healthy } \\
\text { Subjects (n }=9 \text { ) }\end{array}$ \\
\hline $\begin{array}{l}\text { Divided Attention Task } \\
\text { Omissions }(\mathbb{F}=1.04)^{b} \\
\text { Reaction time }(F=5.92)^{c}\end{array}$ & $\begin{array}{l}15.3(9.1) \\
1.49(0.22)+\hbar\end{array}$ & $\begin{array}{l}11.0(6.4) \\
1.10(0.35) \uparrow\end{array}$ & $\begin{array}{l}11.6(4.6) \\
1.18(0.15) \$\end{array}$ \\
\hline $\begin{array}{l}\text { Stroop Color Word } \\
\text { Interference Test } \\
\text { Subtask I } \\
\text { Subtask II } \\
\text { Subtask III } \\
\text { Subtasks III - II }(F=7.29)^{c}\end{array}$ & $\begin{array}{c}51.43(19.01) \\
62.00(18.73) \\
104.01(37.06) \\
42.01(20.57)+\ddagger\end{array}$ & $\begin{array}{l}36.08(4.46) \\
45.70(4.89) \\
64.35(6.75) \\
18.65(3.10) \dagger\end{array}$ & $\begin{array}{l}38.88(3.14) \\
46.62(4.59) \\
74.56(11.27) \\
27.94(8.92) \ddagger\end{array}$ \\
\hline $\begin{array}{l}\text { Verbal Memory Test } \\
\text { Total score }(\mathrm{F}=3.00)^{d}\end{array}$ & $43.89(9.73)$ & $53.67(11.88)$ & $53.02(5.72)$ \\
\hline
\end{tabular}

All results are presented as means, with the standard deviation given in parentheses. $F(1,26)$ values (ANOVA) are given for each test. A common symbol $(\uparrow,+)$ signifies a statistically significant difference according to the Duncan Multiple Range Test.

Not significant.

c $P<0.01$.

$d P<0.1$. 
the patients without PCS and the healthy controls. In contrast, there were no significant differences between the patients without PCS and the healthy control subjects. To check the possible biasing effects of fatigue, the mean reaction time of subjects in the first half of the test was compared with that in the second half. ANOVA revealed no significant group effect [F( $(1.32)=1.3$, nonsignificant], indicating that each group had about the same reaction times in both halves of the test. Although patients with PCS tended to make more omissions, there was no significant overall difference between the three groups for this parameter (Table 2).

\section{DISCUSSION}

There has been considerable debate about whether minor head injuries result in significant persistent cerebral damage and, if present, whether this damage can be demonstrated by using psychometric tests. There is accumulating evidence to indicate that even $\mathrm{MH} 1$ may produce subtle cognitive deficits (15). These deficits appear selectively to impair functions of attention and information processing and are most consistently seen in conjunction with more complex and demanding tasks $(11,15,22,24)$. Studies in patients with MHI cover a heterogeneous population, as there are subgroups of patients who recover quickly, within days, whereas others have persistent PCS after the first weeks of recovery. It is possible that these subgroups represent varying degrees of posttraumatic brain dysfunction. It is important to compare a group of MHI patients experiencing PCS with both MHI patients without PCS and healthy subjects when seeking to establish a meaningful relation between MHI and PCS. The present study indicates that patients with persistent PCS 6 months after an uncomplicated MHI had neuropsychological deficits, as compared with MHI patients without PCS and healthy subjects. The present results are in accordance with those of Dikmen et al. (8) and Leininger et al. (17), and indicate that symptomatic MHI patients displayed significantly poorer performance than controls on several neuropsychological tests. Deficits were most evident on tests of divided and selective attention.

Although we only found a trend towards decreased performance on the verbal memory tests, Leininger et al. (17) found that $\mathrm{MHI}$ patients symptomatic 1 to 22 months after injury had decreased scores on a verbal memory test. The Stroop Color Word Interference Test has been used to measure selective attention in patients with head injury (14). Results consistently indicate that head-injured patients have no specific difficulty in focusing on the color dimension of the ambiguous stimuli when data are aggregated at a group level without reference to the persistence of $\operatorname{PCS}(1,6)$. In contrast, McLean et al. (23) found a significant interference effect on the Stroop test only in the subacute stage after injury. We found that patients with persistent PCS at 6 months had more difficulties with the Stroop Color Word Interference measure than asymptomatic patients and healthy controls. Recently, Gentilini et al. (11) reported further evidence for deficits in selective attention in mildly head-injured patients.

Patients with PCS reacted significantly slower on the divided attention task than the asymptomatic patients and healthy controls. Fatigue can be discarded as a causative factor, because the cognitive deficits were already present in the first half of the task. Although these impairments in attention may appear to be subtle, they may have very disabling consequences. Impaired attention and information processing may adversely affect performance in a vocation that entails decision making or stress (15). Patients are less efficient in the processing of information under time pressure and in demanding situations. Moreover, the demands placed on a mildly head- injured patient at a given point in time after injury are greater than that placed on a victim of severe head injury (25). The real-life consequences of slight disturbances in complex information processing in MHI patients have not been investigated as yet.

With respect to the persistence of symptoms following MHI, Gronwall and Wrightson (12) reported that information processing functions were impaired during the first weeks, with recovery occurring by 35 days, unless the posttraumatic symptoms persisted. These authors suggested that a reduction in the rate of information processing is an important factor in the genesis of the postconcussion syndrome. Similarly, Jakobson et al. (16) were able to predict behavioral recovery 1 month after minor head injury by using a reaction time task. In contrast, MacFlynn et al. (22) found no relationship between measures of reaction time and behavioral sequelae. Whether cognitive deficits underlie or contribute to the behavioral sequelae has to be considered in the perspective of different factors, such as the selection of a particular cognitive test, the environmental demands placed upon a patient (21), and the nature of particular postconcussive symptoms. For example, MacFlynn et al. (22) demonstrated that patients with a symptom cluster of vomiting, vertigo, and diplopia had neurophysiological abnormalities, but did not differ in mean reaction time from patients without this symptom cluster.

The critical question is whether the lower neuropsychological performance of symptomatic patients was caused by the injury or whether neuropsychological dysfunctions were already present before the injury. Given the small sample size and lack of information on the patients' premorbid condition, no firm conclusion can be drawn. Patients were, however, strictly matched on educational level. In addition, none of the patients was unemployed because of the trauma. The presence of symptoms was scored for their appearance after the injury in comparison with the pretraumatic condition. Despite the persistence of symptoms, all patients had resumed their work within 3 months after the injury, with one patient being forced to stop working for a second time. Although none of the patients experienced a symptom-free interval within the first period after the trauma, the resumption of work was a common cause of aggravation of their symptoms.

There is a complex relation between head injury and depression. It is now widely believed that depression may occur after head injury (20), and may compromise cognitive functioning (30). Therefore, symptoms of pre- or posttraumatic psychopathology need to be considered in the evaluation of patients with cognitive dysfunction. Patients with a neuropsychiatric history were excluded from the study. Although postconcussive patients may demonstrate depression, none of the patients with an uncomplicated MHI developed symptoms of a depressive syndrome or posttraumatic stress disorder in the present study.

In summary, the subgroup of MHI patients who report PCS at 6 months after an uncomplicated MHI may demonstrate deficits on tests of attention and information processing. The present findings provide an objective basis for the sometimes vague complaints and symptoms of patients after an uncomplicated MHI. In contrast, patients who had recovered from an uncomplicated MHI did not differ in cognitive functioning from healthy control. subjects. The less adequate neuropsychological functioning of symptomatic patients is important and warrants further investigation. Further research should be aimed at a more integrated approach using a combination of cognitive and neurophysiological or neuroimaging measures, to investigate whether MHI patients with persisting PCS may have evidence of structural brain damage. 
Received for publication, April 10, 1991; accepted, final form, October $311,1991$.

Reprint requests: N. Bohnen, Department of Health Sciences Research, Mayo Clinic, Harwick 6, Rochester, MN 55905.

\section{REFERENCES}

1. Acker MB, Davis JR: Psychology test scores associated with late outcome in head injury. Neuropsychology 3:123-133, 1989.

2. Barth JT, Macciocchi SN, Giordani B, Rimel R, Jane JA, Boll TJ: Neuropsychological sequelae of minor head injury. Neurosurgery $13: 529-533,1983$.

3. Binder LM: Persisting symptoms after mild head injury: A review of the post-concussive syndrome. J Clin Exp Netropsychol 8: $323-346,1986$

4. Brand $\mathrm{N}$, Jolles J: Learning and retrieval of words presented auditorily and visually. J Gen Psychol 1 12:201-210, 1985 .

5. Brooks DN, Aughton ME, Bond MR, Jones B, Rivzi S: Cognitive sequelae in relationship to early indices of severity of brain damage after severe blunt head injury. J Neurol Neurosurg Psychiatry $43: 529-534,1980$

6. Chadwick O, Rutter M, Brown G, Shaffer D, Traub M: A prospective study of children with head injury: II. Cognitive sequelae. Psychol Med 1 1:49-62, 1981.

7. Conover WJ, Iman RL: Rank transformations as a bridge between parametric and non-parametric statistics. Am Statist 35:124-129, 1981.

8. Dikmen S, Mclean A, Temkin N: Neuropsychological and psychosocial consequences of minor head injury. 1 Neurol Neurosurg Psychiatry 49:1227-1232, 1986 .

9. Dikmen S, Temkin N, Armsden G: Neuropsychological recovery: Relationship to psychosocial functioning and postconcussional complaints, in Levin HS, Eisenberg HM, Benton AL (eds): Mild Head Injury. New York, Oxford University Press, 1989, pp 229241.

10. Gentilini M, Nichelli P, Schoenhuber R, Bortolotti P, Tonelli L, Falasca A, Merli GA: Neuropsychological evaluation of mild head injury. J Neurol Neurosurg Psychiatry 48:137-140, 1985.

11. Gentilini M, Nichelli P, Schoenhuber R: Assessment of attention in mild head injury, in Levin HS, Eisenberg HM, Benton AL (eds): Mild Head Injury. New York, Oxford University Press, 1989, pp $163-175$.

12. Gromwall D, Wrightson $P$ : Delayed recovery of intellectual function after minor head injury. Lancet 2:605-609, 1974 .

13. Gronwall D, Wrightson P: Memory and information processing capacity after minor head injury. I Neurol Neurosurg Psychiatry $44: 889-895,1981$.

14. Gronwall D: Advances in the assessment of attention and information processing after head injury, in Levin HS, Grafman J, Eisenberg HM (eds): Neurobehavioral Recovery from Head Injury. New York, Oxford University Press, 1987, pp 355-371.

15. Hugenholtz $H_{3}$, Stuss DT, Stethem LL, Richard MT: How long does it take to recover from a mild concussion? Neurosurgery $22: 853-858,1988$.

16. Jakobsen J, Baadsgaard SE, Thomsen S, Henriksen PB: Prediction of post-concussional sequelae by reaction time test. Acta Neurol Scand $75: 341-345,1987$.

17. Leininger BE, Gramling SE, Farrell AD, Kreutzer JS, Peck EA III: Neuropsychological deficits in symptomatic minor head injury patients after concussion and mild concussion. I Neurol Neurosurg Psychiatry 53:293-296, 1990.

18. Levin HS, Mattis S, Ruff RM, Eisenberg HM, Marshall LF, Tabaddor K, High WM, Frankowski RF: Neurobehavioral outcome following minor head injury: A three-centen study. I Neurosurg $66: 234-243,1987$.

19. Lezak MD: Neuropsychological Assessment. New York, Oxford University Press, 1983, ed 4.

20. Lishman WA: Physiogenesis and psychogenesis in the post-concussional syndrome." Br J Psychiatry 153:460-469, 1988.

21. Long CJ, Novack TA: Postconcussion symptoms after head trauma: Interpretation and treatment. South Med J 79:728-732, 1986.
22. MacFlyn G, Montgomery EA, Fenton GW, Rutherford W: Measurement of reaction time following minor head injury. $J$ Neurol Neurosurg Psychiatry 47:1326-1331, 1984.

23. McLean A, Temkin NR, Dikmen $S$, Wyler AR: The behavioural sequelae of head injury. J Clin Neuropsychol $5 ; 361-376,1983$.

24. McMillan TM, Glucksman EE: The neuropsychology of noderate head injury. I Neurol Neurosurg. Psychiatry 50:393-397, 1987.

25. Ponsford J: Psychological sequelae of closed head injury: Time to redress the imbalance. Brain Injury 4:11 $1-114,1990$.

26. Rimel RW, Giordani B, Barth JT, Ball JT, Jane JA: Disability caused by minor head injury. Neurosurgery $9: 221-228,1981$.

27. SAS User's Guide: Statistics. Version 5. Cary, NC, SAS Institute Inc., 1985

28. Teasdale $G$, Jennett $B$ : Assessment of coma and impaired consciousness: A practical scale. Lancet 2:81-84, 1974.

29. Verhage R: Intelligenic en leefijd. Doctoral dissertation. Assen, The Netherlands, 1964.

30. Weingartner $\mathrm{H}$, Siberman $\mathrm{E}$. Models of cognitive impairment: Cognitive changes in depression. Psychopharmacol Bull $18: 27$ 42,1982

\section{COMMENTS}

The persistence and pathogenesis of postconcussional symptoms after an uncomplicated mild head injury continue to generate controversy. The contributions of this study include the direct comparison of patients exhibiting postconcussional symptoms at 6 months after a mild head injury versus patients sustaining apparently similar injuries whose symptoms resolved by 6 months. Using experimental tests of attention, the investigators were able to show that the symptomatic patients had a residual cognitive impairment relative to the asymptomatic patients and a normal control group. Other assets of the study include exclusion of patients with preexisting neuropsychiatric disorders and the use of multivariate statistics. The authors acknowledge the possibility that depression may have contributed to the attention deficit of their patients; however, without assessment of depression and evaluation of the patients at an earlier time after injury, the potential role of depression cannot be determined.

A second explanation for the persistence of symptoms and attention deficits in 9 of the 46 patients is the possibility of heterogeneity in injury. A recent study by Williams et al. (I) showed that patients with Glasgow Coma Scale scores of 13 to 15 who had evidence of a brain lesion on a computed tomographic scan exhibited more severe neuropsychological sequelae and residual disability than other patients with mild impairment of consciousness who had normal computed tomographic findings. In the present study, the authors do not report computed tomographic findings. Consequently, it is unclear whether the symptomatic patients may have sustained a brain lesion similar to the complicated patients reported by Williams et al. In any case, Bohnen and co-workers provide further evidence for heterogeneity in the mild head injury population. Elucidation of the basis of this heterogeneity in outcome awaits further research.

Harvey S. Levin Galveston, Texas

1. Williams DH, Levin HS, Eisenberg HM: Mild head injury classification. Neurosurgery 27:422-428, 1990.

If repeated knock-outs by blows to the head lead to subsequent mental deterioration (1), does one transient knock-out produce any mental decline? Monkeys subjected to a solitary blow with momentary loss of consciousness suffer disruption of axons in their brain (2). Somewhat more severe but class- 
ifiably mild head injuries do appear to produce long-term mental deficits (3). Such considerations suggest that head injuries producing brief (e,g., seconds, an hour) loss of consciousness can produce detectable long-term decrements in mental performance.

The current manuscript is a welcome addition to an emerging body of evidence that suggests that such "minor" head injuries may have long-term sequelae. Bohnen, Jolles, and Twijnstra offer us data indicating that such is the case, and provide an informative review of the literature. Their data concern patients who incurred transient loss of consciousness of no more than 15 minutes. They compare the patients who complained of two or more postconcussive symptoms 6 months later with those who did not. Additional comparison is made with a group selected to be matched controls. Patients with persistent symptoms at 6 months did less well than either of the other groups on a small, predetermined group of neuropsychological tests. The results suggest that minor head injuries can result in longer term mental performance deficits.

The caveats to this study are well discussed. They include the possibility that the symptomatic postconcussive group was already emotionally and/or cognitively different before the head injury. Furthermore, it is possible that neuropsychological test performance was diminished by the patients" symptoms or some other related noncognitive factor. It must also be noted that none of the patients studied appears to have had computed tomographic scans done at the time of injury.

If, indeed, such minor head injuries prove to be capable of producing measurable deficits, we will have to grapple with the functional costs and implications of these findings in the areas of head injury prevention and rehabilitation.

Ralph A. W. Lehman Hershey. Pennsylvania

1. Council on Scientific Affairs (American Medical Association). Brain injury in boxing. JAMA 249:254-257, 1983.

2. Jane JA, Steward O, Gennarelli TA. Axonal degeneration induced by experimental noninvasive minor head injury. J Neurosurg $62: 96-100,1986$.

3. Rimel RW, Giordani B, Barth JT, Boll TJ, Jane JA. Disabulity caused by minor head injury. Neurosurgery 9:221-228, 1981. 